\title{
A Guerra de Canudos e a construção discursiva euclidiana
}

Alice Baroni

\section{Resumo:}

O artigo se propõe a interpretar a construção do discurso do verdadeiro no acontecimento a Guerra de Canudos, a partir da obra Os sertões, de Euclides da Cunha. Para enriquecer a pesquisa, as reportagens escritas por Cunha, enquanto correspondente pelo jornal $O$ Estado de $S$. Paulo, também serão analisadas. Utilizamos ao longo do texto a expressão "efeitos de verdade", que é uma expressão do filósofo francês Michel Foucault que diz respeito aos discursos não serem em si nem falsos nem verdadeiros. Em Os sertões, os efeitos de verdade surgem através das relações estratégicas e de poder entre a igreja católica, os senhores das terras, os políticos e um Brasil do litoral desconhecedor do Brasil dos sertões, no acontecimento a Guerra de Canudos.

\section{Palavras Chave:}

Discurso, poder, verdade.

\begin{abstract}
:
This article sets out to interpret the construction of truth discourse in the War of Canudos, through the classic Os sertões, by Euclides da Cunha. To enrich the research, the articles wrote by Cunha, while he was a war correspondent for the $O$ Estado de S. Paulo newspaper, will be analyzed, too. Along with the text, the expression "truth-effects" designed by French philosopher Michel Foucault is being used. "Effects of truth" is an expression in reference to the idea of discourses being neither true nor false. In Os sertões, the effects of truth emerge from strategic power disputes amongst the Church, landowners, politicians and a seaside ruling elite that ignores the reality of the poor and forsaken hinterlands.
\end{abstract}

\section{Keywords:}

Discourse, power, truth.

Euclides da Cunha publicou dois artigos com o nome A nossa Vendéia (1). O primeiro em 14 de março de 1897 e o segundo em 17 de julho do mesmo ano, ambos publicados no jornal $O$ Estado de S. Paulo. O artigo de 14 de março foi publicado logo após a assombrosa notícia enviada da Bahia da derrocada da $3^{a}$ expedição e morte do general Moreira César. "Os artigos estabelecem uma comparação que ficaria célebre e seria muito utilizada por todos, ao equiparar o levante na Bahia com aquele de caráter religioso e contrarrevolucionário coligando camponeses e nobres em reação à Revolução Francesa” (GALVÃO, 2000: 11).

No primeiro artigo, Euclides da Cunha escreve sobre a região do Vale do Ipiranga, conhecida também como Vaza Barris, lugar de instalação do arraial canudense. Escreve sobre o solo, a vegetação e o clima. O que é interessante, no entanto, de se observar nesse primeiro artigo são os primeiros indícios de uma tentativa de compreensão, de construção, do que venha a ser o sertanejo, de sua imbricada relação com a terra. A terra, nesse artigo, já desponta como protagonista da luta. $\mathrm{O}$ projeto euclidiano, que apresenta o consórcio entre a arte e a ciência, já dá mostras nesse primeiro momento. Pois não há a cisão entre o homem e a natureza, ao 
contrário, o sertanejo e o solo, e vice-versa, estão em completa sintonia: "Identificados à própria aspereza do solo em que nasceram, educados numa rude escola de dificuldades e perigos, esses nossos patrícios do sertão, de tipo etnologicamente indefinido ainda, refletem naturalmente toda a inconstância e toda a rudeza do meio em que se agitam. $\mathrm{O}$ homem e o solo justificam assim de algum modo, sob um ponto de vista geral, a aproximação histórica expressa no título do artigo" (CUNHA, 2000: 50-51).

Euclides da Cunha inicia o entre-tecimento entre o homem e a terra. A sua impressão do sertanejo, nesse momento, é o de um homem fanatizado, ingênuo e simples, à mercê dos propagandistas do Império. Euclides da Cunha estabelece relação entre o fanatismo sertanejo e o dos chouans, culminando no "mesmo heroísmo mórbido difundido numa agitação desordenada e impulsiva de hipnotizados" (CUNHA, 2000: 51). Assim, Cunha constrói o paralelo entre chouan e o sertanejo. Enquanto aquele fazia uso das charnecas para prender as forças republicanas nas ciladas, a terra para este realiza o papel de protagonista da batalha. Ronaldes de Melo e Souza aponta a importância da questão da terra em Os sertões. A terra euclidiana é Terra com letra maiúscula por ressaltar o seu caráter protagonístico no conflito. Euclides encerra o seu primeiro artigo, no entanto, com um viva à República: "Este paralelo será, porém, levado às últimas consequências. A República sairá triunfante desta última prova" (CUNHA, 2000: 52). Em seu texto, "Euclides da Cunha apresentou aos leitores da época o perfil do que considerava o componente fundamental e misterioso do conflito, o sertão. Deste modo individualizou e destacou matéria das notícias então vinculadas pelos jornais, superando a repetição tediosa dos relatos sobre aqueles eventos mais ou menos desconhecidos e contornando a algaravia dos republicanos exaltados" (AVIGHI, 1987: 146).

O artigo de 17 de julho de 1897 foi publicado já no clima da quarta expedição, comandada por Artur Oscar de Andrade Guimarães. Essa expedição reuniu, inicialmente, 4.283 homens, divididos em seis brigadas. À data da publicação, a expedição já havia partido há um mês de Jeremoabo e Monte Santo, e o general Amaral Savaget, comandante da segunda coluna, já havia sido ferido.

Com o intuito de compreender a tática de guerra dos sertanejos, inimigos intangíveis, Euclides da Cunha a comparou com os conflitos entre as forças inglesas contra os zulus e os afghans, com o conflito francês em Madagáscar e com as forças italianas contra os abissínios. Carlos Marcos Avighi observa sobre a exemplificação de fatos internacionais para aclarar a compreensão sobre a Guerra de Canudos: "Euclides da Cunha demonstrou o profundo conhecimento do que ocorria no mundo, assim exercendo um jornalismo interpretativo de qualidade" (AVIGHI, 1987: 149).

Não era a primeira vez que Euclides da Cunha escrevia sobre o inimigo intangível. No primeiro artigo, Euclides já havia feito referência a ele, no entanto, no artigo de 17 de julho, o articulista investe na compreensão da região, da terra, da sensação de imobilidade da paisagem para poder compreender o sertanejo, o jagunço, em íntima comunhão com o meio. Assim, Euclides da Cunha escreve sobre o jagunço (2) que afeito à paisagem selvagem a transpõe facilmente. Ressalta também a sua vestimenta toda feita de couro curtido, das alparcatas ao chapéu de abas largas, sábia proteção contra os espinhos que sequer a ferem. "Não há persegui-lo no seio de uma natureza que o criou à sua imagem - bárbaro, impetuoso, abrupto" (CUNHA, 2000: 57). O articulista percebe que não há como compreender a guerra sem compreender a simbiose entre o homem e a terra. "A conjunção ambiente-homem, segundo Euclides da Cunha, era o forte entrave à vitória das forças governamentais" (AVIGHI, 1987: 150). Mas não é apenas a terra que colabora com o jagunço: "O jagunço é uma tradução justalinear quase do iluminado da Idade Média. O mesmo desprendimento pela vida e a mesma indiferença pela morte, dão-lhe o mesmo heroísmo mórbido e inconsciente de hipnotizado e impulsivo. Uma sobriedade extraordinária garante-lhe a existência no meio das maiores misérias" (CUNHA, 2000: 58).

Euclides da Cunha insiste com o tema da simbiose entre homem e meio quando escreve sobre o favorecimento da natureza a favor do jagunço, com a confecção de armamento para o seu rústico arsenal, "as 
cavernas numerosas que se abrem nas camadas calcárias dão-lhes o salitre para a composição da pólvora e os leitos dos córregos, lastrados de grãos de quartzo duríssimos e rolados, são depósitos inexauríveis de balas" (CUNHA, 2000: 59).

A publicação dos artigos A nossa Vendéia foi fundamental para a escolha de Euclides da Cunha como correspondente na campanha de Canudos, pelo jornal O Estado de S. Paulo: "Não foi, assim, de surpreender quando o jornal paulista incumbiu o articulista de ser seu correspondente de guerra, especialmente enviado ao palco dos acontecimentos. Por essa época já as principais folhas do Rio e da Bahia se tinham adiantado a $O$ Estado de S. Paulo e mandado os seus, publicando regularmente a cobertura dos acontecimentos a partir de julho e agosto" (GALVÃO, 2000: 12).

Mas, antes de partir, Euclides da Cunha fez uso de seu tempo para ampliar o arcabouço teórico sobre o sertão e o sertanejo. Sobre o preparo euclidiano escreveu Avighi:

O jornalista ampliava seu instrumental teórico e acumulava informações sobre os fatos e a região que iria noticiar. Cumpria o dever do jornalista opinativo, do articulista que deveria estar o mais pronto possível para interpretar e avaliar com segurança e sustentar suas idéias no foro da opinião pública. Acrescentou aos conhecimentos adquiridos nas leituras sobre o Brasil as informações mais precisas acerca do homem e da natureza que encontraria. Em São Paulo, quem melhor conhecia os personagens do drama sertanejo era Teodoro Sampaio, amigo certo e diálogo elucidativo que já em outras oportunidades contribuíra para o trabalho de Euclides da Cunha. Percorrera os quadrantes nordestinos ainda lacunados nos mapas da época, trabalhando e pesquisando (AVIGHI, 1987: 169).

Assim, acompanhando a comitiva do ministro da guerra, marechal Carlos Machado Bittencourt, Euclides da Cunha embarcou no navio Espírito Santo, do Rio de Janeiro em direção à Bahia, em três de agosto de 1897. Chegaria em Salvador no dia sete de agosto e ficaria na capital baiana até o dia trinta. De lá partiria de trem para Alagoinhas e Queimadas, e de cavalo para Tanquinho, Cansanção, Quirinquinquá e Monte Santo, chegando em Canudos no dia dezesseis de setembro. A partida de Euclides da Cunha de Canudos foi alvo de discussão por muitos anos. Por fim, José Calasans, em 1969 cita uma publicação no Diário da Bahia, de 17 de outubro de 1897, que dizia da partida de Euclides da Cunha de Canudos no dia 3 de outubro do mesmo ano.

Em Os sertões, Euclides da Cunha retoma o paralelo com a Vendéia, mas de uma forma muito mais dramática. Destituído do véu encobridor dos acontecimentos, Euclides percebe o equívoco de se ter cantado fácil vitória sobre os rebelados sertanejos. Cabe a fina reflexão de Euclides da Cunha:

Malgrado os defeitos do confronto, Canudos era a nossa Vendéia. O chouan e as charnecas emparelham-se bem com o jagunço e as caatingas. O mesmo misticismo, gênese da mesma aspiração política; as mesmas ousadias servidas pelas mesmas astúcias, e a mesma natureza adversa, permitiam que se lembrasse aquele lendário recanto da Bretanha, onde uma revolta, depois de fazer recuar exércitos destinados a um passeio militar por toda a Europa, só cedeu ante as divisões volantes de um general sem fama, "as colunas infernais"' do general Turreau - pouco numerosas mas céleres, imitando a própria fugacidade dos vendeanos, até encurralá-los num círculo de dezesseis campos entrincheirados. Não se olhou, porém, para o ensinamento histórico. É que se preestabelecera a vitória inevitável sobre a rebeldia sertaneja insignificante (CUNHA, 2003: 314).

Várias eram as vozes que interferiam e interpretavam a questão canudense. O governo baiano defendia serem suficientes as medidas tomadas. $\mathrm{O}$ grupo de rebelados e fanáticos, que somavam pouco mais de quinhentos, logo seria extinto, não sendo necessário o reforço das forças federais. O chefe militar argumentava pelo fortalecimento das forças federais, que deveriam seguir fortes, pois o intuito não era mais o de prender 
criminosos, mas o de "extirpar o móvel de decomposição moral que se observava no arraial de Canudos em manifesto desprestígio à autoridade e às instituições" (CUNHA, 2003: 315). Já o governo estadual interpretava a questão canudense como ameaça à soberania nacional, a partir do artigo $6^{\circ}$ da Constituição de 24 de fevereiro. Repelia a intervenção por considerar-se "desarmado para suplantar a revolta", "apelando para os recursos da União" (CUNHA, 2003: 315).

Estavam fincadas as bases para a intervenção da União. Rapidamente foi removido o chefe da força militar da Bahia, seguindo reforçada a coluna do major Febrônio pela tropa policial, "adstrita às deliberações do governo baiano" (CUNHA, 2003: 316). Enquanto isso, ao largo do tempo que se desenrolou para a reconstituição da estratégia federal, o inimigo aparelhava-se para o revide: "Num raio de três léguas em roda de Canudos, fizera-se o deserto. Para todos os rumos e por todas as estradas e em todos os lugares, os escombros carbonizados das fazendas e dos pousos avultavam, insulando o arraial num grande círculo isolador, de ruínas. Estava pronto o cenário para um emocionante drama da nossa história" (CUNHA, 2003: 316).

Em 21 de janeiro de 1895, o Diário de Notícias da Bahia publicou a seguinte manchete: "Sofrimento do povo brasileiro causado pela trindade maldita: a peste, a fome e a guerra" (SAMPAIO, 1999: 49). Manchete que, segundo a historiadora Consuelo Sampaio, induzia o leitor a pensar que a guerra referida dizia respeito a Canudos, sendo que em verdade se referia à questão política, à luta pelos interesses pessoais dos políticos, que se sobrepunha à questão canudense. Consuelo Novais Sampaio, comentando a manchete, escreveu sobre a época de Canudos (1893-1897): "Os membros da elite baiana estavam muito envolvidos na luta por cargos na administração pública, no Legislativo e no Judiciário, que então se organizavam.

Questiúnculas partidárias e de interesse pessoal não lhes permitiam desviar a atenção para uma multidão de romeiros decididos a acampar em Belo Monte. Foi a disputa pelo poder, na Bahia e na capital federal, que conferiu a Canudos dimensão nacional" (SAMPAIO, 1999: 53).

Percebe-se que a formação do discurso oficial constrói-se a partir de relações de poder, estratégias e interesses políticos dos senhores da terra e conselheiros políticos. O processo de reconstrução do passado nos abre portas para a interpretação do sertão, do sertanejo e do senhor de terra, de suas relações imbricadas de poder e suas formações discursivas. O acontecimento 'Guerra de Canudos' surge imbuído de complexidade irredutível de simples resposta. Os sertões é a grande mostra de irredutibilidade dos acontecimentos observados. O olhar para o passado também nos traz o entendimento sobre o profundo desconhecer do interior do Brasil à época de Euclides da Cunha. Ajuda-nos a refletir como se formaram os discursos equivocados sobre a guerra, o sertanejo e os senhores de terra. Os sertões, obra-monumento, instaura o processo de des-velamento do palco dos acontecimentos em Canudos, destecendo os fios condutores das formações discursivas.

A lucidez do narrador euclidiano ilumina o drama gnosiológico dos sertões. Em seu livro-vingador, Euclides da Cunha destrincha os erros da campanha canudense, a ignorância dos soldados sobre a guerra, a terra e o homem sertanejo; expõe Moreira César como "um desequilibrado. Em sua alma a extrema dedicação esvaíase no extremo ódio, a calma soberana em desabrimentos repentinos e a bravura cavalheiresca na barbaridade revoltante" (CUNHA, 2003: 371). Além disso, apresenta-nos o fracasso, os erros de sua investida sobre o arraial de Canudos. É impressionadora a lucidez narrativa euclidiana que apresenta o arraial canudense em sua máxima fragilidade e formidável força e resistência. Nas reportagens escritas do palco dos acontecimentos, Euclides da Cunha faz referência à região do arraial de Canudos, à conformação de suas casas e ruas estreitas, mas apenas em Os sertões o narrador euclidiano será capaz de pronunciar:

Canudos, entretecido de becos de menos de dois metros de largo, trançados, cruzando-se em todos os sentidos, tinha ilusória fragilidade nos muros de taipa que o formavam. Era pior que uma cidadela 
inscrita em polígonos ou blindada de casamatas espessas. Largamente aberto aos agressores que podiam derruí-lo a coices de arma, que podiam abater-lhe a pulso as paredes e tetos de barro ou varálo por todos os lados, tinha a inconsistência e a flexibilidade traiçoeira de uma rede desmesurada. Era fácil investi-lo, batê-lo, dominá-lo, varejá-lo, aluí-lo; era dificílimo deixá-lo. Completando a tática perigosa do sertanejo, era temeroso porque não resistia. Não opunha a rijeza de um tijolo à percussão e arrebentamento das granadas, que se amorteciam sem explodirem, furando-lhe de uma vez só dezenas de tetos. Não fazia titubear a mais reduzida secção assaltante, que poderia investi-lo, por qualquer lado, depois de transposto o rio. Atraía os assaltos, e atraía irreprimivelmente o ímpeto das cargas violentas, porque arremetida dos invasores, embriagados por vislumbres de vitória e disseminando-se, divididos pelas vielas em torcicolos, lhe era o recurso tremendo de uma defesa surpreendedora. Na história sombria das cidades batidas, o humílimo vilarejo ia surgir com um traço de trágica originalidade. Intacto - era fragílimo; feito escombros - formidável (CUNHA, 2003: 420-421).

Euclides da Cunha finaliza a construção narrativa da derrota das tropas de Moreira César no arraial canudense com a força da frase: "Ora, as tropas do coronel Moreira César faziam-na desabar sobre si mesma" (Id.: 421).

\section{A caminho do palco da guerra}

A situação em Canudos era de incerteza, quando Euclides da Cunha embarcou no navio Espírito Santo. Por toda a nação ouvia-se o grito dominante: A República está em perigo! Precisamos salvá-la. A guerra atingira o momento decisivo, como aponta Avighi. Canudos seria esmagada ou a opinião pública iria acompanhar a derrota "da maior e mais potente força enviada contra os insurrectos" (AVIGHI, 1987: 159). Euclides da Cunha escreveu em Os sertões sobre a comoção em que se formou a quarta expedição.

A quarta expedição organizou-se através de grande comoção nacional, que se traduziu em atos contrapostos à própria gravidade dos fatos. Foi a princípio o espanto; depois um desvairamento geral da opinião; um intenso agitar de conjeturas para explicar o inconceptível do acontecimento o induzir uma razão de ser qualquer para aquele esmagamento de uma força numerosa, bem aparelhada e tendo chefe de tal quilate. Na desorientação completa dos espíritos, alteou-se logo, primeiro esparsa em vagos comentários, condensada depois em inabalável certeza, a idéia de que não agiam isolados os tabaréus turbulentos. Eram a vanguarda de ignotas falanges prontas a irromperem, de remanente, em toda a parte, convergentes sobre o novo regímen. E como nas capitais, federal e estaduais, há muito, meia dúzia de platônicos, revolucionários contemplativos e mansos, se agitavam esterilmente na propaganda da restauração monárquica, fez-se de tal circunstância ponto de partida para a mais contraproducente das reações (CUNHA, 2003: 449-450).

O comandante-em-chefe, general Artur Oscar, e sua tropa estavam cercados por conselheiristas no morro da Favela. A segunda coluna combatia em Cocorobó sob o comando do general Cláudio do Amaral Savaget, mas sofriam feroz resistência. Chegavam notícias sobre os ataques à Brigada Auxiliar, que tinha ido ao encontro das duas colunas, mas que teria ficado desfalcada antes mesmo de atingir o lugar ambicionado. Para completar o quadro, as levas de feridos que retornavam da frente de batalha para Salvador horrorizavam a opinião pública. Sem falar das inúmeras mortes de oficiais renomados, de alta patente. Batalhões se formavam em diferentes regiões do Brasil com o intuito de se juntar às tropas em combate: "Euclides da Cunha, em 'A Nossa Vendéia', já esmiuçara a precariedade da estratégia governamental e registrara que, ao invés da desordem a ser esmagada por tropas bem aparelhadas, Canudos era um confronto prolongado a exigir administração de recursos militares" (AVIGHI, 1987: 158).

Euclides da Cunha e os outros correspondentes na guerra sofreram inúmeras dificuldades para exercer o ofício do jornalismo, especialmente por motivo de sigilo das informações. Um grande empecilho era o fato de o ministro da guerra não conceder entrevistas, coisa que não fez em nenhum momento da campanha. Os 
correspondentes tinham de se desdobrar em busca de novas fontes para receber e checar as informações recebidas. Embora o marechal Carlos Machado Bittencourt, ministro da guerra, conversasse bastante com Euclides da Cunha, "mantinha em sigilo as decisões e os planos" (AVIGHI, 1987: 171).

O primeiro despacho enviado por Euclides da Cunha, intitulado A bordo do Espírito Santo, denuncia a falta de informações sobre a campanha. A reportagem de 7 de agosto de 1897 descreve a emoção da partida; um discurso emocionado sobre a saudade dos soldados. À exceção da observação de Euclides da Cunha no que se refere à incoerência do morteiro Canet, artilharia moderna de guerra da época, para o combate nos sertões, o texto se tece de imagens sentimentais e lugares comuns.

A disposição entre os oficiais é a melhor possível. A saudade, imensa e indefinível saudade dos entes queridos ausentes, desce, às vezes, profunda, dolorosíssima e esmagadora sobre os corações: as frontes anuviam-se; cessam bruscamente as palestras em que se procura afugentar tristezas numa guerrilha adoidada de anedotas; um pesado silêncio paira repentinamente sobre os grupos esparsos; o coração batendo febrilmente nos peitos, perturba o ritmo isócrono da vida - e os olhares, velado de lágrimas, dirigem-se ansiosamente para o Sul... Ao mesmo tempo, porém, como um antídoto enérgico, um reagente infalível, alevanta-se, ao Norte, o nosso grande ideal - a República - profundamente consolador e forte, amparando vigorosamente os que cedem às mágoas, impelindo-os à linha reta notabilitadora do dever (CUNHA, 2000: 66-67).

Como observou Carlos Marcos Avighi (1987: 171), Euclides da Cunha "ocupa-se da maior parte das descrições gerais do porto de Salvador, desenvolvendo-se em afirmações discutíveis e concluindo com o indefectível 'A República é imortal'”.

A reportagem seguinte, de 10 de agosto, segundo Avighi, já demonstra o jornalista equilibrado e experiente. Para o pesquisador, a frase de abertura da reportagem euclidiana é digna de ser equiparada a um texto jornalístico moderno: "Dizem os mais antigos habitantes da Bahia que nunca ela se revestiu da feição assumida nestes últimos dias" (CUNHA, 2000: 68). Avighi ainda observa que com a frase: "Velha cidade tradicional, conservando melhor do que qualquer outra os mais remotos costumes, a sua quietude imperturbável desapareceu de todo" (Ibid., p, 68-69), Euclides da Cunha "enseja ao leitor o clima da guerra naqueles lugares e o predispõe para as informações que transmitirá, utilizando, então, o recurso do contraponto ao descrever os soldados que retornam" (AVIGHI, 1987: 173): "(...) soldados que voltam mutilados e combalidos da luta, soldados que seguem entusiastas e fortes para a campanha. E presa nesse fluxo e refluxo de mártires que chegam e de valentes que avançam, sob o contágio dominador da febre que lavra nas almas dos combatentes, galvanizada pelo mesmo entusiasmo, ela parece ligar, através de longos anos de apatia, os dias atuais aos dias agitados das lutas da Independência" (CUNHA, 2000: 69).

Mas, no que diz respeito ao nosso objeto de pesquisa, o que nos é importante ressaltar na reportagem do dia 10 de agosto é a construção mitopoética que Euclides da Cunha realiza ao compor a imagem do jagunço. Sobre o discurso dos soldados que retornavam da frente de batalha, Euclides da Cunha escreveu: "o jagunço degolado não verte uma xícara de sangue" e "o fanático morto não pesa mais que uma criança" (CUNHA, 2000, p.75). Euclides da Cunha faz referência ao jagunço como "tais seres" possuidores da "agilidade de símios", que deslizam como cobras pela caatinga "resvalando céleres, descendo pelas quebradas, como espectros, arrastando uma espingarda que pesa quase tanto como eles - magros, secos, fantásticos" (CUNHA, 2000: 75-76). Sobre a pele do jagunço, escreveu Cunha (2000: 76): "peles bronzeadas coladas sobre os ossos - ásperas como peles de múmias...". Os "tais seres", o jagunço, emerge no discurso euclidiano de 10 de agosto como um ser não humano imbricado à Terra (3), à região, à caatinga, em profunda, íntima, comunhão com o sertão.

Em Os sertões, Euclides da Cunha aprofunda, desenvolve, o que vem a ser o sertanejo realizando também a 
comparação com o gaúcho. A obra dividida em três partes realiza um estudo aprofundado sobre a Terra, o Homem e a Luta. Ao contrário das reportagens escritas por Euclides da Cunha quando acompanhava a comitiva do ministro da guerra, o marechal Bittencourt, que realiza o percurso de Euclides da Cunha pelos sertões, o seu livro-vingador reconstrói não apenas os antecedentes da campanha, como realiza um estudo muito mais aprofundado sobre o que venha a significar a terra, o homem e a luta, para a Guerra de Canudos. Esperamos demonstrar também que, em Os sertões, Euclides da Cunha despiu-se de seus discursos préconcebidos, reconstruindo o passado autêntico do confronto e com isso iluminando o presente. Tentaremos demonstrar que há ainda nas reportagens concessões ao discurso oficial republicano e à linha editorial do jornal que o enviou como correspondente de guerra a Canudos.

Em Os sertões, não por menos denominado o seu livro-vingador, Euclides da Cunha não faz concessões, ao contrário, reconstrói o palco dos acontecimentos como problematização. Questões que nos são colocadas concernentes a inúmeros aspectos da campanha sertaneja. Um deles, por exemplo, trata sobre o fanatismo. Em Os sertões, Euclides expõe o fanatismo soldadesco em relação aos ideais republicanos, fanatismo esse que não aparece em suas reportagens. Há também, em Os sertões, os bárbaros soldados. Em suas reportagens, a barbárie é restrita aos jagunços. Estes emergem no livro-vingador como lutando para defender as suas casas da invasão dos soldados do Estado. Há a degola, barbárie soldadesca. Há, assim, inúmeros exemplos que seguem distintas formações discursivas em Os sertões e nas reportagens escritas ao longo da Campanha. É isto que queremos explorar: a gestação dos discursos. Como os discursos se gestam no Euclides da Cunha jornalista e adido do ministro da guerra, e como vão ser gestados em um Euclides da Cunha engenheiro, reconstrutor de uma ponte na pacata cidade de São José do Rio Pardo. Destituído da pressão da opinião pública, que foi induzida a odiar Antônio Conselheiro, da linha editorial da instituição jornalística e do torvelinho do palco dos acontecimentos, Euclides da Cunha escreveu o que viria a ser o seu livro-vingador. Assim, temos como anseio encontrar os pontos em comum, isto é, os temas abordados nas reportagens e em Os sertões para, a partir do seu estudo comparativo, compreender como se gestaram os discursos em Os sertões e nas reportagens euclidianas. Este é o viés no qual realizaremos a nossa interpretação. Não nos atentando ao que diz respeito aos momentos distintos de Os sertões, a nossa interpretação surge pela compreensão da obra como simbiose, imbricamento profundo, entre o Homem, a Terra e a Luta.

O projeto euclidiano que realiza o consórcio entre a ciência e a arte requereu para a compreensão da luta o empreendimento de compreensão do sertanejo, que se faz todo ele vaqueiro: "À parte a agricultura rudimentar das plantações da vazante pela beira dos rios, para a aquisição de cereais de primeira necessidade, a criação de gado é, ali, a sorte de trabalho menos impropriada ao homem e à terra" (CUNHA, 2003: 166).

Só a partir do entendimento profundo sobre o jagunço para quem "Viver é adaptar-se" (CUNHA, 2003: 164) à terra que "talhou-o à sua imagem: bárbaro, impetuoso, abrupto..." (Ibid.: 164); somente a partir do entendimento do profundo imbricamento entre a terra e o homem e a relação de "servidão inconsciente" (CUNHA, 2003: 167) deste com o senhor das terras, a Guerra de Canudos pode ser desvelada.

Nos telegramas enviados por Euclides da Cunha surgem apontamentos sobre as condições precárias nas quais as tropas se batiam em combate com os conselheiristas. Vejamos o que Euclides da Cunha escreveu no telegrama do dia 8 de agosto de 1897: "Citam-se aqui inúmeros episódios interessantes decorridos durante a luta. No combate de 18 de julho, as tropas legais bateram-se desde as quatro horas da madrugada, às oito da noite, sem beberem uma gota de água!" (CUNHA, 2000: 226). O discurso euclidiano compõe-se a partir de diversas vozes, de possibilidades e divergências discursivas. Como observou Ronaldes de Melo e Souza, nada no discurso euclidiano é estável. Além das condições precárias, Cunha começa a trazer a público os erros cometidos pelas tropas na campanha. "Os oficiais feridos nos últimos combates relatam erros de tática de ordem tão grave que só devem ser expostos, depois de investigações ulteriores e sérias” (Ibid.: 226).

É impressionadora a imagem construída por Euclides da Cunha para retratar a chegada dos feridos que 
retornam da frente de batalha, na reportagem do dia 12 de agosto. Na tentativa de esboçar o trágico quadro, Euclides da Cunha escreveu que o desembarque dos feridos, na estação da Calçada, mostrou-se como "um quadro indefinível com o qual se harmonizariam admiravelmente o gênio sombrio e o pincel funéreo de Rembrandt" (CUNHA, 2000: 76-77). Os oficiais da República, ao contrário de serem esboçados como heróis, surgem sob o olhar de Euclides como "as grandes vítimas obscuras do dever" (Ibid.: 77). "É como uma procissão dantesca de duendes, contemplo-a através de uma vertigem, quase". E segue compondo o quadro: "Considero-os, à medida que passam - coxeando, arrastando-se penosamente, trôpegos, combalidos, titubeantes, imprestáveis - trágicos candidatos à invalidez e à morte...” (CUNHA, 2000: 78).

Nessa mesma reportagem, Cunha escreveu sobre os erros ou equívocos cometidos na guerra e suas funestas consequências. "Não se fez uma guerra, subordinada a preceitos invioláveis - fez-se uma diligência policial com oito mil homens" (Ibid.: 79). Significa dizer que, destituídos dos preceitos invioláveis, a campanha de Canudos desenrolou-se sobre a barbárie. "Perdido no deserto, jungido a provações imensas, muitas vezes sem os mais elementares recursos e sob o ataque persistente e traiçoeiro do inimigo, o soldado brasileiro jamais patenteará abnegação maior" (CUNHA, 2000: 79-80). A ausência dos recursos mais elementares para a realização da campanha parecerá a Euclides da Cunha a Guerra de Canudos como um exemplo único na história. "Dificilmente se encontra, folheando a história inteira, um exército que, já quase faminto de véspera e extenuado de combates, se bate durante catorze horas, da madrugada à noite, sem tomar sequer uma gota de água" (CUNHA, 2000: 80). Sobre as condições de penúria dos combatentes, Euclides da Cunha escreve ainda na reportagem do dia 20 de agosto: "É o combate tenaz, inglório e assustador, a um inimigo que morre e revive todos os dias, envolvendo nos mesmos transes amigos e adversários - a fome" (CUNHA, 2000: 114).

O discurso euclidiano é desconstrutor, pois inverte os elementos. O soldado construído discursivamente para representar o herói nacional surge aos trapos, "turmas extenuadas de retirantes" (Ibid.: 77), ao invés de um exército. Emerge faminto, aos trapos, trôpego, vítima obscura de um dever republicano. A incoerência da guerra canudense, os seus inúmeros erros, o seu aspecto amoral e absurdo surge logo nas reportagens enviadas da Bahia, nos telegramas escritos ao longo da campanha. Os sertões, publicado cinco anos após ter findada a guerra, emergiu como o livro-vingador euclidiano. Nele, a luta é levada às últimas consequências. Surge a degola conhecida como gravata vermelha prática cometida pelos soldados da tropa, que degolaram incontáveis conselheiristas. Surge um outro Brasil até então desconhecido. Surge o brasileiro, sertanejo, vaqueiro e jagunço, que se entrega para a luta, o seu sangue, por ideais que o Brasil do litoral não poderia compreender. Ao trazer à tona a questão da profunda ignorância sobre um Brasil do interior que não é separado pelo litoral, mas por três séculos, Euclides da Cunha constrói a terra, o homem e a luta como uma grande questão para o Brasil e os brasileiros. Em Os sertões, as relações estratégicas e de poder existentes entre a igreja católica, os senhores das terras e os políticos que fazem com que os discursos oficiais sejam tecidos sofrem o destecimento euclidiano, que clarifica e obscurece o palco dos acontecimentos da guerra.

\section{Bibliografia:}

AVIGHI, M. A. Euclides da Cunha jornalista. São Paulo: ECA-USP, 1987 (tese de doutorado).

BONETTI, M. A. C. Teoria semiótica do jornalismo: uma nova perspectiva de estudo para promover a aproximação entre jornalismo e verdade. São Paulo: PUC-SP, 2001 (tese de doutorado).

CASTRO, Manuel Antônio de (org.). A arte em questão: as questões da arte. Rio de Janeiro: 7Letras, 2005.

CUNHA, Euclides da. Os sertões. Edição crítica de Walnice Nogueira Galvão. 2a. ed. São Paulo: Ática, 2000. 
Letras, 2000.

Diário de uma expedição. In: GALVÃO, Walnice Nogueira (org.). São Paulo: Companhia das Os sertões. São Paulo: Ediouro, 2003.

FOUCAULT, Michel. A ordem do discurso. 8a. ed. São Paulo: Loyola, 2002.

. A verdade e as formas jurídicas. 3a. ed. Rio de Janeiro: Nau Editora, 2005.

. Microfísica do poder. 22a. ed. Rio de Janeiro: Graal, 1979.

. Vigiar e punir. 32a. ed. Petrópolis: Vozes, 1987.

. As palavras e as coisas. 8a. ed. São Paulo: Martins Fontes, 1999.

. A arqueologia do saber. 7a. ed. Rio de Janeiro: Forense Universitária, 2004.

HEIDEGGER, Martin. A origem da obra de arte. Lisboa: Edições 70, 2005.

SAMPAIO, Consuelo Novais. Canudos: cartas para o barão. São Paulo: Edusp, 1999.

SOUZA, R. M. "A geopoética de Euclides da Cunha". Net, São José do Rio Pardo, dez. de 2007. Disponível em: http://www.casaeuclidiana.org.br/download/default.asp. Acesso em: 13/01/2007.

SUASSUNA, Ariano. "Euclydes da cunha, canudos e o exército". In: O clarim e a oração: cem anos de Os Sertões. São Paulo: Geração Editorial, 2002, pp.21-23.

\section{Notas:}

(1) Camponeses católicos e monarquistas que lutaram armados contra a Revolução Francesa.

(2) Walnice Nogueira Galvão observa que Euclides da Cunha escreve jagunço grifado demonstrando estranhamento com a paisagem. Esse grifo, no entanto, desaparece em Os sertões.

(3) Terra foi escrito com letra maiúscula para ressaltar o caráter protagonístico que a terra assume na obra euclidiana.

\section{Mini Currículo :}

Mestre em comunicação social pela PUC-RJ e jornalista. Integra o Grupo de Estudos em Jornalismo Impresso e Online. 